\title{
Analysis of passive earth thrust in an unsaturated sandy soil using discontinuity layout optimization
}

\author{
Bestun Shwan ${ }^{\mathrm{a}}$ \\ Department of Civil \& Structural Engineering, University of Sheffield, Mappin Street, Sheffield S1 3JD, UK.
}

\begin{abstract}
This paper addresses a numerical study into passive earth pressure in an unsaturated sandy soil. The computational limit analysis method, discontinuity layout optimization (DLO), is extended to take into consideration the effect of saturation and suction on strength. The extended analysis was utilised to model a retaining wall case study using a sandy soil as a simulated backfill material and the results were compared with Rankine equations which were modified to take into account the capillary rise effect. The numerical results demonstrated that an increase of the total passive thrust up to $47 \%$, for a frictionless wall, at $\phi^{\prime}=30^{\circ}$ due to the effect of partial saturation in the sandy soil.
\end{abstract}

\section{Introduction}

Many historical geotechnical structures such as railway embankments and cuttings were designed before the modern science of soil mechanics was developed. In many cases these structures only stand up due to the strength imparted to them through partial saturation and the effects of surface tension (water suction) acting in the soil pores which holds the soil particles together.

With improved understanding of unsaturated soil mechanics in such conditions, it may be possible to utilise the additional strength due to partial saturation in conventional design e.g. with engineered controls on the saturation, under a risk based framework, in temporary works, or in assessing cumulative cyclic loading effects through the seasons.

Significant efforts during the last two decades have been focused on the field of unsaturated soil mechanics and this has led to the formulation of several constitutive models (for example, [1-4]).

In contrast, the application of unsaturated soil mechanics theory to geotechnical design is much more limited (e.g. [5] and [6]).

Such studies are limited by the nature of what can be dealt with using hand calculations. Recent developments in computational limit analysis (CLA) (e.g. [7]) have extended the scope of such analytical methods, so that they can deal with any geometry and loading configuration, and have been applied in many areas to ultimate limit state (ULS) design.

There is a significant scope to extend CLA to include unsaturated soil behaviour, providing a tool that can find the collapse load for a wide range of problems such as retaining walls or foundation stability without the simplifications inherent in hand calculations or the complexity of the elasto-plastic finite element (FE) method.

The aim of this paper is therefore to extend the application of the CLA method, discontinuity layout optimization (DLO), to model the effects of partial saturation on the passive earth pressure exerted by an unsaturated sandy soil.

\section{Theory}

\subsection{Discontinuity layout optimization (DLO)}

The DLO procedure is a computational limit analysis method that directly identifies the collapse load for stability problems. The procedure allows either the determination of load or strength for any stability problem. The concept of DLO, which is based on the upper bound theorem of plasticity proposed by [7], is built on determining the critical failure mechanism that results in the least amount of energy dissipation.

The basic principle of the DLO is based on recognizing a critical layout of lines of discontinuity to create failure mechanism. These lines are the slipboundaries between the rigid blocks due to the applied loads. A wide range of different failure mechanisms can be produced by utilising high numbers of nodes, then discretizing these nodes by connecting them each to another as shown in Fig. 1.

\footnotetext{
a bjnshwan@gmail.com
} 


\subsection{Energy dissipation and work equation in DLO}

Following [7] and [8] in the presence of water, the rate of internal energy dissipation and work done against body forces for the problem of a Mohr-Coulomb material with self-weight $\gamma$, cohesion $c$ and angle of friction $\phi$ collapsing as a set of sliding blocks where each discontinuity (or interface) $i$ between adjacent sliding blocks has relative shear and normal displacement jumps of $s_{\mathrm{i}}$ and $n_{i}$ can be written as:

$$
E=\sum_{i=1}^{m}\left(c_{i} l_{i} s_{i}+U_{i} n_{i}+W_{i} s_{i} \sin \theta_{i}+W_{i} n_{i} \cos \theta_{i}\right)
$$

where $m$ is the number of interfaces and $U_{i}$, and $W_{\mathrm{i}}$ are respectively the pore water force on, and weight of the strip of soil above interface $i$ and $l_{i}, \theta_{\mathrm{i}}$ are the length of interface $i$ and the angle of interface $i$ to the horizontal. For a limit analysis approach, $n_{i}=\left|s_{i}\right| \tan \phi^{\prime}$.

where $W$ is weight of the soil above a discontinuity (see Fig.2).

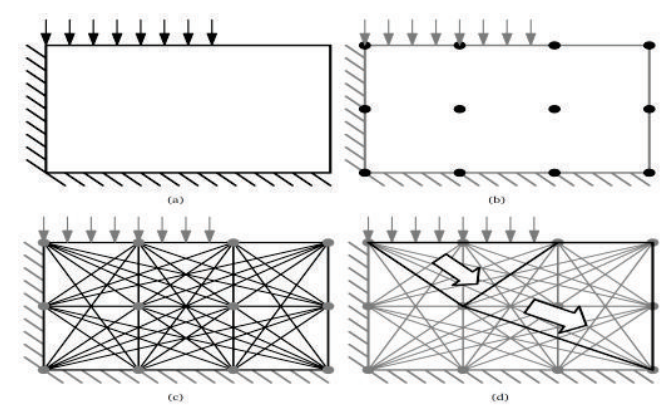

Figure 1. DLO stages procedure, after [8].

\subsection{Incorporation of suctions into DLO}

Stanier and Tarantino [6] proposed equations for shear strength, for compacted aggregated soils in partially saturated conditions, and for suction as follows:

$$
\begin{aligned}
& \tau=\left(\sigma+s S_{r}\right) \tan \phi^{\prime} \\
& s=\gamma_{w}\left(H_{w}-z\right)
\end{aligned}
$$

where $\tau$ is the shear strength $(\mathrm{kPa}), \sigma$ is the total normal stress $(\mathrm{kPa}), s$ is the suction $(\mathrm{kPa}), S_{r}$ is the degree of saturation $\%, \gamma_{w}$ is the unit weight of the water $\left(\mathrm{kN} / \mathrm{m}^{3}\right), H_{w}$ is water table depth (positive downward) (m), $z$ is vertical coordinate (positive downward) (m). Equation (3) assumes full water continuity within the soil.

Shwan and Smith [10] proposed equations for $S_{r}$ as follows:

$$
\begin{aligned}
& S_{r}=1.0 \quad s s_{o} \\
& S_{r}=e^{-a\left(s-S_{O}\right)} \quad s>s_{O}
\end{aligned}
$$

where $a$ is a fitting parameter $\left(\mathrm{kPa}^{-1}\right), s_{\mathrm{o}}$ is the air entry value of the soil $(\mathrm{kPa})$ and it is related to the height of the capillary rise (full saturation) $H_{c}$ as follows:

$$
H_{c}=\frac{s_{o}}{\gamma_{w}}
$$

In order to compute the value of $U$ in Eq. (1) for use in the DLO formulation in a partially saturated soil, the following integration is required:

$$
U=\int_{0}^{L} s S_{r} \cdot d l
$$

where $L$ is length of discontinuity as shown for example in Fig. 2.

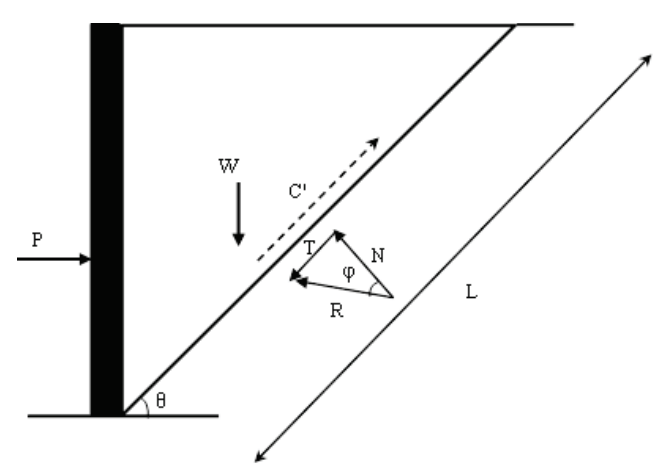

Figure 2. Geometry and features of the total passive earth pressure problem.

Figure 2 shows a simple Coulomb wedge analysis. By equating the work done and the internal energy dissipated, the total passive thrust $\left(P_{p}\right)$ in Fig. 2 can be determined as follows:

$$
P_{p} \delta-W \delta \tan \left(\theta+\phi^{\prime}\right)=c^{\prime} L \cos \left(\phi^{\prime}\right) \frac{\delta}{\cos \left(\theta+\phi^{\prime}\right)}
$$

where $\delta$ is the block displacement, $W$ is the weight above the discontinuity $(\mathrm{kN})$ and $c^{\prime}$ is the cohesion $(\mathrm{kPa})$.

\section{Total passive earth pressure analysis}

\subsection{Case study}

A non-dimensional analysis of the total passive earth pressure for a wall with a levelled backfill is modelled. The boundaries of the backfill are $1 \mathrm{~m}$ height (height of the wall) and $6.2 \mathrm{~m}$ length. Three types of walls are modelled as frictionless, frictional wall with $\delta=(2 / 3)$ $\phi^{\prime}$ and fully frictional wall $\delta=\phi^{\prime}$ and they are named throughout the context of this paper as series FL, 0.67FW and $\mathrm{FW}$, respectively. For series $0.67 \mathrm{FW}$ and $\mathrm{FW}$, the depth of the soil is extended $0.8 \mathrm{~m}$ below the base of the wall to prevent restriction of the failure mechanism by the bottom boundary (see Figs. 5b and c).

In this analysis, the soil is assumed to be fully saturated below the capillary rise height (determined using Eq. 6), while the average unit weight, between dry and saturated unit weight, is utilised above the capillary rise height. Water table height $\left(Y_{w}\right)$ is varied from $1 \mathrm{~m}$ (fully saturated) to $-3 \mathrm{~m}$ below the base of the wall. This represents a degree of saturation range from $100 \%$ to $\approx 0 \%$ and suction from 0 to $39.2 \mathrm{kPa}$ for the sandy soil used according to its soil water characteristic curve SWCC (see Fig. 3).

The soil properties are shown in Table 1 for the sandy soil. Dry and saturated unit weights are assumed as 1.5 and 1.9 of the unit weight of water. This is to keep the 
effect of the unit weight constant while studying the effect of the degree of saturation. A range of internal friction angle values from $30^{\circ}$ to $45^{\circ}$ is utilised for this parametric study.

Parameter $a$ and $s_{\mathrm{o}}$ in Table 1 are obtained using best fit (using Eqs. 4 and 5) for the actual SWCC obtained from the work of [11] as shown in Fig. 3.

Table 1. Soil properties and unsaturated parameters of the

\begin{tabular}{|c|c|c|}
\hline & Material & \\
\hline \multirow{5}{*}{$\begin{array}{c}\text { Soil } \\
\text { properties }\end{array}$} & $c^{\prime}(\mathrm{kPa})$ & 0 \\
\hline & $\gamma_{w}\left(\mathrm{kN} / \mathrm{m}^{3}\right)$ & 9.81 \\
\hline & $\gamma_{\text {sat }}\left(\mathrm{kN} / \mathrm{m}^{3}\right)$ & 18.64 \\
\hline & $\gamma_{d r y}\left(\mathrm{kN} / \mathrm{m}^{3}\right)$ & 14.72 \\
\hline & $\gamma_{\text {average }}\left(\mathrm{kN} / \mathrm{m}^{3}\right)$ & 16.68 \\
\hline \multirow{3}{*}{$\begin{array}{l}\text { Unsaturated } \\
\text { parameters }\end{array}$} & $a\left(\mathrm{kPa}^{-1}\right)$ & 0.1 \\
\hline & $s_{o}(\mathrm{kPa})$ & 5 \\
\hline & $H_{c}(\mathrm{~m})$ & 0.509 \\
\hline
\end{tabular}

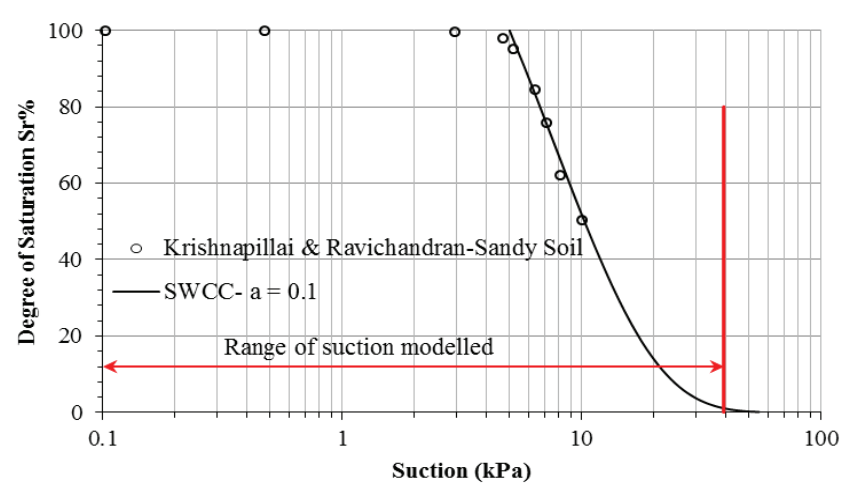

Figure 3. SWCC for sandy soil (after [11]) with the best fit using Eqs. 4 and 5 and a range of the suctions modelled.

\subsection{Results}

Figures $4 \mathrm{a}, \mathrm{b}$ and $\mathrm{c}$ give an example of the design chart in which the $\mathrm{x}$-axis represents normalised total passive thrust $\left(P_{P} / H^{2} \gamma_{w}\right)$ and the y-axis represents normalised water table height $\left(Y_{w} /\left(s_{\mathrm{o}} a H\right)\right)$ for a range of internal friction angles for FL, $0.67 \mathrm{FW}$ and FW series. The results are compared with the Rankine method which takes into account capillary rise height.

The total passive earth thrust equations for a frictionless wall, with a levelled backfill, using the Rankine method for the fully saturated and a case when water table is below the soil surface and capillary rise occurs to the surface are given as follows:

$$
\begin{gathered}
P_{p}=\frac{1}{2} k_{p} \gamma^{\prime} H^{2}+\frac{1}{2} \gamma_{w} Y_{\mathrm{w}}^{2} \\
P_{p}=\left(k_{p}-1\right) \times \gamma_{w} H_{c}^{2}+\frac{1}{2} H_{c}\left[k_{p} \gamma_{s a t} H_{c}-\left(k_{p}-1\right) \gamma_{w} H_{c}\right]+ \\
k_{p} \gamma_{s a t} H_{c} Y_{w}+\frac{1}{2} k_{p} \gamma^{\prime} H_{w}^{2}+\frac{1}{2} \gamma_{w} Y_{w}^{2}
\end{gathered}
$$

where $k_{p}$ is passive earth pressure coefficient based on Fig. $4 \mathrm{~d}$ for all the series, $\gamma^{\prime}$ is buoyant unit weight $\left(\mathrm{kN} / \mathrm{m}^{3}\right), H$ is height of the wall $(\mathrm{m}), \gamma_{w}$ is unit weight of water $\left(\mathrm{kN} / \mathrm{m}^{3}\right), Y w$ is water table height $(\mathrm{m})$ (positive upwards), $H_{c}$ is distance from the water table to the capillary rise line and $\gamma_{\text {sat }}$ is saturated unit weight $\left(\mathrm{kN} / \mathrm{m}^{3}\right)$. The derivation of Eq. 10 is based on full continuity of water between the soil and the wall. A capillary rise height $H_{c}=0.509 \mathrm{~m}$ is used shown in Table 1 based on Eq. 6 .

It can be seen from Figs. $4 \mathrm{a}, \mathrm{b}$ and $\mathrm{c}$ that an increase of about $46.8 \%, 54.2 \%$ and $54.2 \%$ can be obtained in $\left(P_{P} / H^{2} \gamma_{w}\right)$ for the case of $\phi^{\prime}=30^{\circ}$ at $Y_{w}=-0.6 \mathrm{~m}$ (corresponding to $Y_{w} /\left(s_{o} a H\right)=-1.2$ in Figs. $4 \mathrm{a}, \mathrm{b}$ and c) for the series FL, $0.67 \mathrm{FW}$ and FW when compared to their counterpart total passive thrust result using the Rankine method. The height $Y_{w}=-0.6 \mathrm{~m}$ corresponds to a maximum normalized $P p$ value, to a hydrostatic suction of $15.696 \mathrm{kPa}(1.6 \times 9.81)$ and degree of saturation of about 34\% (see Fig. 3).

At depth $Y_{w}=-3 \mathrm{~m}\left(Y_{w} /\left(s_{o} a H\right)=-6\right.$ in the Figs. $4 \mathrm{a}, \mathrm{b}$ and $\mathrm{c})$, the $\left(P_{P} / \mathrm{H}^{2} \gamma_{w}\right)$ for the unsaturated case at $\phi^{\prime}=30^{\circ}$ is closer to the result of the Rankine method. No further drop of the water table beyond $3 \mathrm{~m}$ below the base of the wall is carried out as the overall trend of the curves is clear.

Sharper curves can be seen for the higher $\phi^{\prime}$ values at the same $Y_{w}$. For example, for series FL (Fig. 4a) at $Y_{w} /\left(s_{o} a H\right)=-1.2$ for $\phi^{\prime}=45^{\circ}$, higher total passive thrust can be seen when compared to the case of $\phi^{\prime}=40^{\circ}$ at the same $Y_{w}$. This increase is inherently due to the effect of $\phi^{\prime}$ in the term $\left(s S_{r}\right) \tan \phi^{\prime}$ (see Eq. 2).

Figures 5a, b and $\mathrm{c}$ show the failure mechanisms obtained by the modified DLO method for the FL, $0.67 \mathrm{FW}$ and FW series at $Y_{w}=-0.6 \mathrm{~m}$ and $\phi^{\prime}=45^{\circ}$. The FW series reveals a wider and deeper failure mechanism compared to the other two cases due to the effect of the friction of the wall.

\section{Conclusions}

A parametric study on the total passive earth thrust analysis using a simulated sandy soil backfill material was investigated. The following conclusions were demonstrated:

1. A theoretical extension to the Discontinuity Layout Optimization (DLO) procedure to allow the modelling of partially saturated soils has been described, and includes the combined effects of suction and saturation.

2. The influence of partial saturation on the passive earth problem was investigated by utilizing a range of suction profiles and $\phi^{\prime}$ values. A nonlinear relationship for the total passive earth pressure with the water table depth was determined with total passive pressure initially increasing with increased suction and then followed by a reduction as the saturation of the soil fell. 


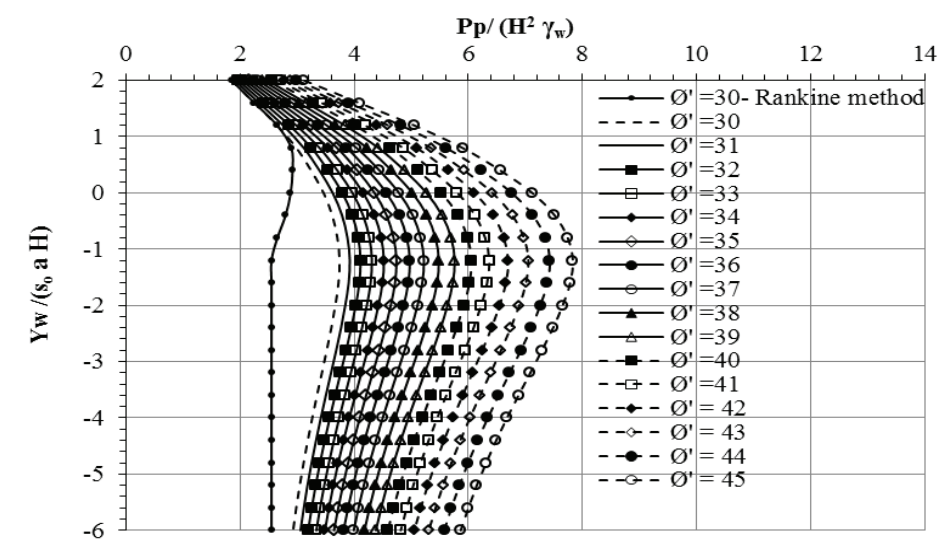

(a)

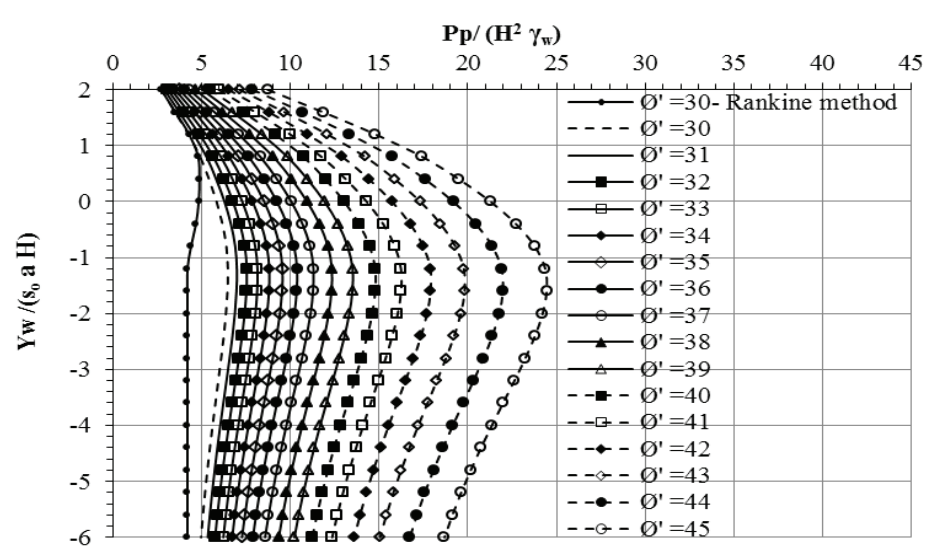

(b)

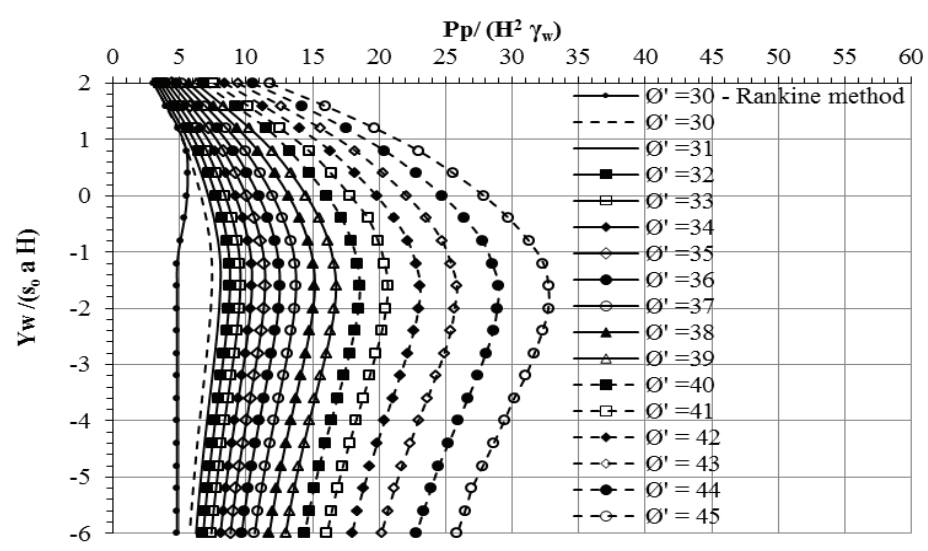

(c) 


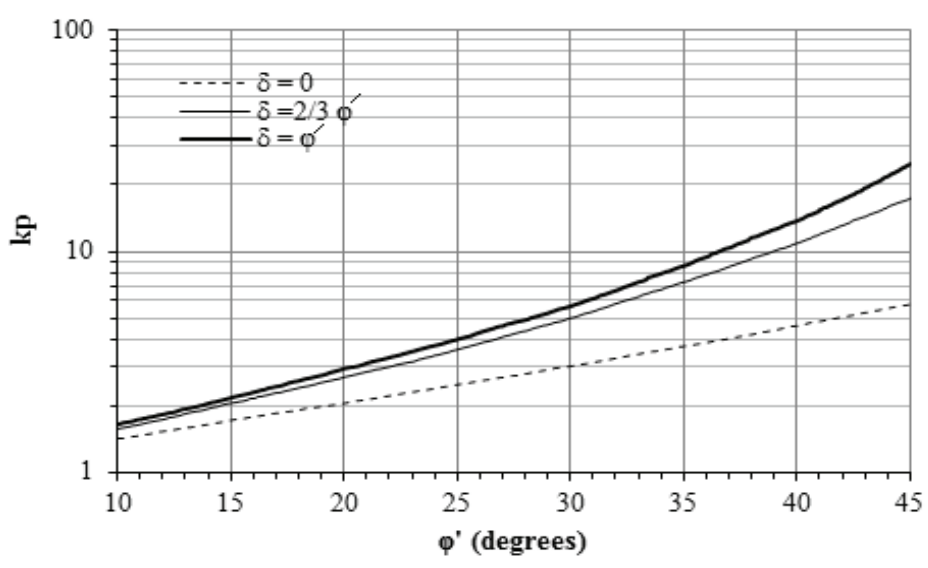

(d)

Figure 4. Normalised $\left(P_{P} / H^{2} \gamma_{w}\right)$ versus normalised $Y_{w} /\left(s_{o} a H\right)$ at a range of the internal friction angle values for (a) FL (b) $0.67 \mathrm{FW}$ (c) FW (d) Passive earth pressure coefficient for various design values of $\phi^{\prime}$ for all three series FL, 0.67FW and FW based on [12].
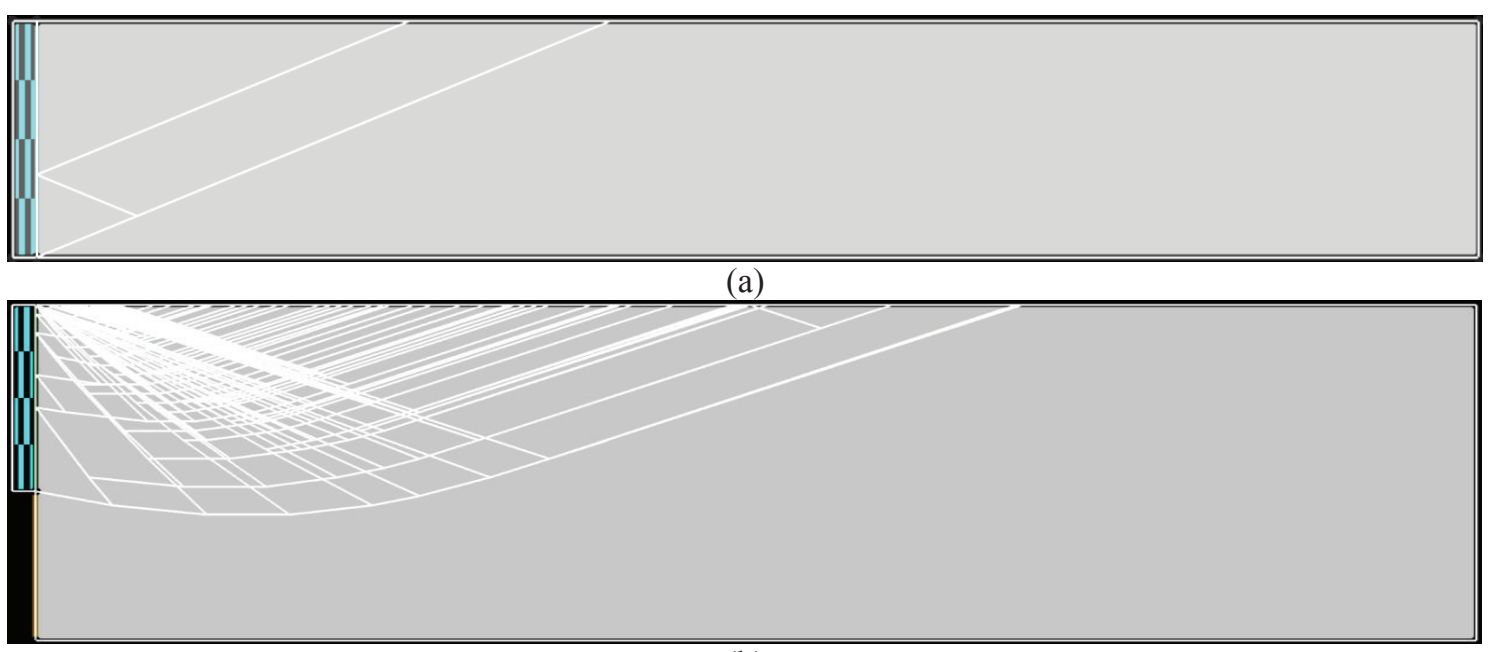

(b)

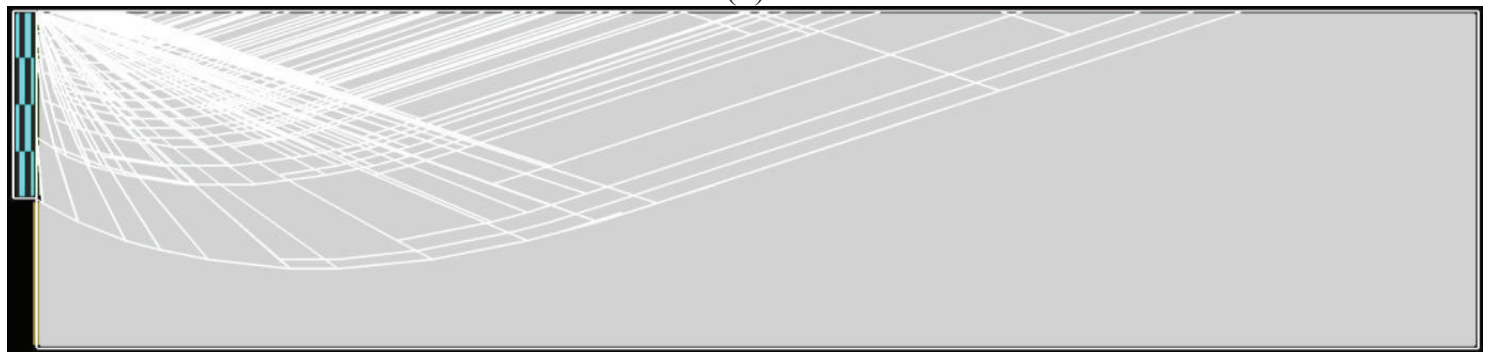

(c)

Figure 5. Failure mechanism obtained by the DLO method at $Y_{w}=-0.6 \mathrm{~m}, \phi^{\prime}=45^{\circ}$ for (a) FL (b) $0.67 \mathrm{FW}$ (c) FW.

\section{Acknowledgments}

The author wishes to acknowledge the financial support which was provided by the Ministry of Higher EducationKurdistan (Iraq) for this work. 


\section{References}

1. E.E. Alonso, A. Gens, A. Josa, A constitutive model for partially saturated soils. Ge'ot. J. 3, pp 405-430 (1990).

2. S.J. Wheeler, An alternative framework for unsaturated soil behaviour. Ge'ot. J. 41(2), pp 257-261, (1991).

3. S.J. Wheeler, V. Sivakumar, An ealso-plastic critical state framework for unsaturated soil. Ge'ot. J. 45(1), 35-53 (1995).

4. A. Tarantino, A possible critical state framework for unsaturated compacted clay. Ge'ot. J. 57, pp 385-389, (2007).

5. L.H. Zhao, Q. Luo, L. Li, F. Yang, X.L. Yang, The upper bound calculation of passive earth pressure based on shear strength theory of unsaturated soil. Proc. of Slope Stability, Retaining walls and Foundatios, ASCE, pp 151157, (2009).

6. S. Stanier, A. Tarantino, Active earth force in 'cohesionless' unsaturated soils using bound theorems of plasticity, In: Alonso, E.E., Gens, A. (Eds.), Proc. of $5^{\text {th }}$ Int. Conf. on Unsat. Soils, CRC Press, Barcelona, Spain, pp 1081-1086, (2010).

7. C. C. Smith, M. Gilbert, Application of discontinuity layout optimization to plane plasticity problems. Proc. R. Soc., A 463, pp 2461-2484, (2007a).

8. C. C. Smith, M. Gilbert, New upper bound solutions for layered soil bearing capacity problems using discontinuity layout optimazation. In: Proc. $10^{\text {th }}$ Australia New Zealand Conf. Geo. Mechs., Brisbane, (2007b).

9. M. Gilbert, C. Smith, I. Haslam, T. Pritchard, Application of discontinuity layout optimization to geotechnical limit analysis problems. In: Proc. $7^{\text {th }}$ Eur. Conf. Num. Meths. Geo. Eng., Trondheim, Norway, pp 169-174, (2010).

10. B. J. Shwan, C.C. Smith, Application of limit analysis in unsaturated soils: numerical and experimental study of bearing capacity. In Unsat. Soils: Res. and Appl. - Proc. $6^{\text {th }}$ Int. Con. Unsat. Soils, Sydney, Australia, pp 1757-1762, (2014).

11. S. H. Krishnapillai, N. Ravichandran, New soilwater characteristic curve and Its performance in the finite-element simulation of unsaturated soils. Int. J. Geo., 12, pp 209-219, (2012).

12. B. Standard, Eurocode 7: Geotechnical design, (2004). 